\title{
Relative availability of natural prey versus livestock predicts landscape suitability for cheetahs Acinonyx jubatus in Botswana
}

Hanlie EK Winterbach, Christiaan W Winterbach, Lorraine K Boast, Rebecca Klein, Michael J Somers

Prey availability and human-carnivore conflict are strong determinants that govern the spatial distribution and abundance of large carnivore species and determine the suitability of areas for their conservation. For wide-ranging large carnivores such as cheetahs (Acinonyx jubatus), additional conservation areas beyond protected area boundaries are crucial to effectively conserve them both inside and outside protected areas. Although cheetahs prefer preying on wild prey, they also cause conflict with people by predating on especially small livestock. We investigated whether the distribution of cheetahs' preferred prey and small livestock biomass could be used to explore the potential suitability of agricultural areas in Botswana for the long-term persistence of its cheetah population. We found it gave a good point of departure for identifying priority areas for land management, the threat to connectivity between cheetah populations, and areas where the reduction and mitigation of human-cheetah conflict is critical. Our analysis showed the existence of a wide prey base for cheetahs across large parts of Botswana's agricultural areas, which provide additional large areas with high conservation potential. Twenty percent of wild prey biomass appears to be the critical point to distinguish between high and low probable levels of human-cheetah conflict. We identified focal areas in the agricultural zones where restoring wild prey numbers in concurrence with effective human-cheetah conflict mitigation efforts are the most immediate conservation strategies needed to maintain Botswana's still large and contiguous cheetah population. 


\section{Relative availability of natural prey versus livestock predicts landscape suitability for cheetahs Acinonyx jubatus in Botswana}

Hanlie E. K. Winterbach, Tau Consultants (Pty) Ltd, Maun, Botswana, and Centre for Wildlife Management, University of Pretoria, Pretoria, South Africa.

Christiaan W. Winterbach, Tau Consultants (Pty) Ltd, Maun, Botswana, and Centre for Wildlife Management, University of Pretoria, Pretoria, South Africa.

Lorraine K. Boast, Cheetah Conservation Botswana, Private Bag BO 284, Gaborone, Botswana.

Rebecca Klein, Cheetah Conservation Botswana, Private Bag BO 284, Gaborone, Botswana.

Michael J. Somers, Centre for Wildlife Management, University of Pretoria, Pretoria, South Africa, and Centre for Invasion Biology, University of Pretoria, Pretoria, South Africa.

Corresponding author: Hanlie E. K. Winterbach, Private Bag 83, Maun, tel: +26772782522 , tauconsultants@gmail.com 


\begin{abstract}
2 Prey availability and human-carnivore conflict are strong determinants that govern the spatial

3 distribution and abundance of large carnivore species and determine the suitability of areas for

4 their conservation. For wide-ranging large carnivores such as cheetahs (Acinonyx jubatus),

5 additional conservation areas beyond protected area boundaries are crucial to effectively

6 conserve them both inside and outside protected areas. Although cheetahs prefer preying on wild

7 prey, they also cause conflict with people by predating on especially small livestock. We

8 investigated whether the distribution of cheetahs' preferred prey and small livestock biomass

9 could be used to explore the potential suitability of agricultural areas in Botswana for the long-

10 term persistence of its cheetah population. We found it gave a good point of departure for

11 identifying priority areas for land management, the threat to connectivity between cheetah

12 populations, and areas where the reduction and mitigation of human-cheetah conflict is critical.

13 Our analysis showed the existence of a wide prey base for cheetahs across large parts of

14 Botswana's agricultural areas, which provide additional large areas with high conservation

15 potential. Twenty percent of wild prey biomass appears to be the critical point to distinguish

16 between high and low probable levels of human-cheetah conflict. We identified focal areas in the

17 agricultural zones where restoring wild prey numbers in concurrence with effective human-

18 cheetah conflict mitigation efforts are the most immediate conservation strategies needed to

19 maintain Botswana's still large and contiguous cheetah population.
\end{abstract}




\section{Introduction}

22 The cheetah is Africa's most endangered felid (Marker et al., 2007) and is listed as Vulnerable

23 with a declining population trend in the IUCN Red List of Threatened Species (Durant et al.,

24 2008). Botswana is important for the regional and global long-term survival of cheetahs. It has a

25 large and still contiguous cheetah population, and hosts the second largest national population

26 with \pm 1786 animals (Klein, 2007) after Namibia with $\pm 3138-5775$ animals (Hanssen \&

27 Stander, 2004; Marker et al., 2007). It also forms the major connecting range for the southern

28 African cheetah population, which is the largest known free-ranging resident population

29 comprising \pm 6500 animals (IUCN/SCC, 2007).

30 At least $75 \%$ of the cheetah's resident range in southern Africa falls outside protected areas

31 (IUCN/SSC, 2007), mostly on farmlands where competition with other large carnivores is low

32 and a sufficient small to medium-sized wild prey base still occurs (Marker \& Dickman, 2004;

33 Klein, 2007; Lindsey \& Davies-Mostert, 2009). Cheetahs are one of the most wide-ranging

34 terrestrial carnivores and need extensive areas to sustain viable populations (IUCN/SCC, 2007;

35 Belbachir et al., 2015). Interspecific competition, especially from lions (Panthera leo) and

36 spotted hyaenas (Crocuta crocuta), is suggested as one of the main reason for this wide-ranging

37 behaviour as it can strongly influence their movements, behaviour and density (Durant, 2000;

38 Broekhuis et al., 2013). Competition between cheetahs and their dominant competitors occurs

39 predominantly inside protected areas, where densities of lions and spotted hyaenas tend to be

40 high (Creel, Spong \& Creel, 2001). With few protected areas large enough to contain the ranging

41 behaviour of cheetahs, the provision of additional areas beyond protected area boundaries is

42 necessary to effectively conserve them both inside and outside protected areas (Woodroffe \& 
43 Ginsberg, 1998). Consequently, conservation efforts in human-dominated landscapes are critical

44 for the cheetah's long-term survival.

45 The two primary factors influencing large carnivore survival is prey availability and conflict 46 with humans (Winterbach et al., 2013). The strong linear relationships that exist between the 47 density of African large carnivores and the biomass of their natural prey (Hayward, O'Brien \& 48 Kerley, 2007) point to prey availability as the primary natural determinant that governs the 49 spatial distribution and abundance of large carnivore species, and hence the suitability of an area 50 for their conservation (Gittleman \& Harvey, 1982; Fuller \& Sievert, 2001; Hayward, O'Brien \& 51 Kerley, 2007; Broekhuis et al., 2013). However, although cheetahs prefer wild prey (Marker et 52 al., 2003), they also cause conflict with people by preying on livestock, usually small stock 53 (sheep and goats) and occasionally calves and foals (Marker et al., 2003; Ogada et al., 2003; 54 Woodroffe et al., 2007; Selebatso, Moe \& Swenson, 2008). As a result, in human-dominated 55 landscapes, human activities and conflicts with predators often become as strong a determining 56 factor as prey availability in the existence of large carnivores, including cheetahs (Woodroffe \& 57 Ginsberg, 1998; Marker et al., 2003; Gusset et al., 2009; Schuette, Creel \& Christianson, 2013). 58 In 2009, the Botswana Department of Wildlife and National Parks (DWNP) drafted a national conservation action plan for the country's cheetahs and African wild dogs. One of the primary 60 targets set out in the action plan is to obtain quantitative knowledge regarding the main threats to 61 securing a viable cheetah population across its range in Botswana. Scientific information on 62 cheetah distribution and density on a country-wide scale, however, is nearly impossible to obtain, 63 but the urgent conservation status of this species means we can ill-afford to wait for detailed 64 scientific information before policy decisions are made. Therefore, an objective, clear system of 
65 evaluation, based on the best available and reliable information is needed, that can be used as a

66 basis to support policy setting (Theobald et al., 2000).

67 In this study we aimed to assess potentially suitable habitat across Botswana for the long-term

68 persistence of cheetahs using wild prey distribution and a proxy for probable human-cheetah

69 conflict. Such an assessment is especially important in the extensive agricultural areas used

70 primarily for raising livestock, where around half of Botswana's cheetah population occurs

71 (Winterbach \& Winterbach, 2003). Data from country-wide aerial survey counts of both wild

72 prey and livestock were the best available information for this assessment. We calculated cheetah

73 prey biomass from the aerial counts of wild species likely to be utilized by cheetahs in Botswana.

74 As a proxy for probable levels of human-cheetah conflict, we calculated the proportion of

75 cheetah prey biomass relative to the combined biomass of wild prey and small livestock. By

76 combining this information with country-wide reports of human-cheetah conflict, we created a

77 predictive map of landscape suitability for cheetahs. This approach to making a landscape

78 assessment for a specific species on a national scale is unique, and generated fundamental

79 knowledge that can inform decisions regarding land management, connectivity between cheetah

80 sub-populations, and human-cheetah conflict mitigation. The predictive map highlighted some

81 important implications for the conservation of cheetahs in Botswana, which we discuss.

\section{Study Area}

85 The Republic of Botswana is ca $582000 \mathrm{~km}^{2}$ in size and is landlocked with Namibia, South

86 Africa, Zimbabwe, and Zambia as its neighbours. Roughly $50 \%$ of its 2 million people (3.5

87 people $/ \mathrm{km}^{2}$ ) live in rural villages and small settlements (Central Statistics Office, 2014). 
The mean altitude above sea level is $1000 \mathrm{~m}(515$ - $1491 \mathrm{~m}$ a.s.1.). The climate is arid to semi-arid with highly variable rainfall and severe droughts. Mean annual rainfall varies from 650 $\mathrm{mm}$ in the north-east to $250 \mathrm{~mm}$ in the south-west. Average maximum daily temperatures range

91 from $22^{\circ} \mathrm{C}$ in July to $33^{\circ} \mathrm{C}$ in January and average minimum temperatures from $5^{\circ} \mathrm{C}$ to $19^{\circ} \mathrm{C}$, 92 respectively (Department of Surveys and Mapping, 2001). The country has only two perennial 93 rivers; the Okavango River which fans out into the Okavango Delta and the Kwando/

94 Linyanti/Chobe river system which forms the boundary with Namibia and Zambia. The Makgadikgadi Pans is a seasonal wetland with natural perennial water holes in the ephemeral Boteti River providing critical dry season water sources for wildlife in Makgadikgadi Pans National Park. Across the rest of the country, scattered pans and ancient riverbeds periodically hold water during the wet season. Considerable seasonal variations in the density and distribution of ungulate species occur and the blocking of migration routes by veterinary fences has led to ungulate die-offs during drought years (Verlinden, 1998; Bergström \& Skarpe, 1999). Seasonal migrations of Burchell's zebra and blue wildebeest (Connochaetes taurinus) still occur inside

102 Makgadikgadi Pans National Park (Brooks, 2005), and zebra migrate between Makgadikgadi

103 Pans National Park and the Okavango Delta (Bartlam-Brooks, Bonyongo \& Harris, 2011).

104 Approximately $38 \%$ of the land use in Botswana is designated for wildlife utilization; $17 \%$ as

105 protected areas (national parks and game reserves) and 21\% as Wildlife Management Areas. The

106 latter are primarily designed for wildlife conservation, utilisation, and management (Hachileka,

107 2003). The Northern Conservation Zone consists of Chobe, Nxia Pan, and Makgadikgadi Pans

108 National Parks, Moremi Game Reserve in the Okavango Delta, and Wildlife Management Areas.

109 The Central Kalahari Game Reserve and Kgalagadi Transfrontier Park are linked with Wildlife

110 Management Areas to form the Southern Conservation Zone. Protected areas and Wildlife 
111 Management Areas do not have 'predator-proof' fences, with the exception of the western and

112 southern boundary of Makgadikgadi Pans National Park which provides only a partial barrier

113 due to lack of maintenance.

114 Five percent of the country is urban, $57 \%$ is rangeland (of which roughly $70 \%$ is tribal /

115 communal grazing land), $25 \%$ is state land, and $5 \%$ is freehold land leased for large-scale

116 commercial ranching (Department of Surveys and Mapping, 2001). In the Draft National

117 Predator Strategy (Winterbach \& Winterbach, 2003), the country was sub-divided into two main

118 predator management zones: the Conservation Zone comprises national parks, forest reserves,

119 sanctuaries, and Wildlife Management Areas; the Agricultural Zone comprises rangelands,

120 residential, and mining areas (Figure 1).

121 Livestock (mainly cattle) rearing is the primary economic activity over large parts of

122 Botswana and constitutes $70-80 \%$ of the agricultural GDP (Botswana Ministry of Agriculture,

123 2011). In the 2012 household survey, the livestock population in Botswana was estimated as

1242.6 million cattle, 1.8 million goats, and 300,000 sheep, most of which were located on the more

125 fertile eastern side of the country. Approximately $92 \%$ of these livestock are farmed traditionally

126 using the cattle post system on communal grazing land. Botswana's key environmental issues

127 include water scarcity and pollution, rangeland degradation and desertification, loss of

128 biodiversity, deforestation, and an increased frequency of periodic droughts (Wingqvist \&

129 Dahlberg, 2008).

130

\section{Methods}

132 
133 Cheetah wild prey were represented by those animal species counted in aerial surveys across

134 Botswana that are within the accessible prey weight range (body mass $14-135 \mathrm{~kg}$ ) for cheetahs

135 identified by Clements et al. (2014) (Table 1), hereafter termed 'cheetah prey'. For small

136 livestock we used goats and sheep (hereafter referred to as 'small stock') as the main livestock

137 whose depredation is a significant predictor of human-cheetah conflict levels, as illustrated by

138 problem animal control (PAC) reports from DWNP (Data S1). The source of the estimated

139 number of each prey species and small stock was the Botswana Aerial Survey Information

140 System database (Botswana Government, 2000), which holds the annual dry-season country-

141 wide survey data.

142 We calculated the mean number per cheetah prey species for each 12' grid cell

143 (approximately $21 \times 22 \mathrm{~km}$ ) for the 2001 to 2005 and 2007 surveys. We excluded the survey

144 conducted in 2006, as it only covered northern Botswana, and those conducted during the

145 drought years before 2001 and very wet years after 2007. This was done to avoid including

146 counts from extreme years when large variations in population estimates is likely. The mean

147 number per species were then converted to species biomass in Large Stock Units (LSU), using

148 the formula $\mathrm{LSU}=$ number of animals $\times$ body weight ${ }^{0.75}$ (Meissner, 1982), and summed to

149 provide the total cheetah prey and small stock biomass, respectively, per grid cell. We calculated

150 the percentage that cheetah prey biomass contributed to the total biomass consisting of cheetah

151 prey and small stock (hereafter referred to as 'percentage cheetah prey' biomass), where a low

152 percentage indicated high probable levels of conflict (Data S2).

153 Cheetah biomass strongly correlates with dry season prey biomass (Fuller \& Sievert, 2001),

154 and we felt the combined data set of the six aerial surveys used in this study best represented the

155 general distribution of prey and small stock biomass on a country-wide scale. Although aerial 
156 surveys tend to undercount small mammal species such as steenbok (Raphicerus campestris) and

157 duiker (Sylvicapra grimmia) (Jachmann, 2002), it is the only feasible method for wildlife

158 monitoring over such large areas. We utilized the existing broad landscape suitability

159 stratification for large carnivores in Botswana from Winterbach, Winterbach \& Somers (2014),

160 and refined the agricultural zones to identify homogeneous strata based on the distribution of

161 cheetah prey biomass, small stock biomass, and percentage cheetah prey biomass.

162 We tested the hypothesis that percentage cheetah prey was correlated with the level of

163 conflict. We used data on livestock attacks by cheetahs between 1995 and 2006 consisting of

164 PAC reports, and farms questionnaire surveys $(N=188)$ conducted during 2004 and 2005

165 (Klein, 2007), to determine if the number of livestock attacks changed with the percentage

166 cheetah prey. We used the following intervals of percentage cheetah prey: $0,>0$ to $\leq 1,>1$ to $\leq 2$,

$167>2$ to $\leq 5,>5$ to $\leq 10,>10$ to $\leq 20,>20$ to $\leq 80$, and $>80$ to $\leq 100$, and determined the number of

168 grid cells and the number of reported attacks per interval. Then we calculated the number of

169 attacks per grid cell for each interval and the overall mean number of attacks per grid cell.

170 We used a chi square test to determine if the number of grid cells (expected values) and the

171 number of livestock attacks (observed values) differed significantly for the following categories

172 of percentage cheetah prey: $0,>0$ to $\leq 20,>20$ to $\leq 80$, and $>80$ to $\leq 100$. Observations were

173 classified into categories independently and all categories had expected frequencies $>5 \%$. We

174 used Bonferroni intervals (Byers, Steinhorst \& Krausman, 1984) to test for categories with

175 observed frequencies that differed significantly from the expected. Based on the results, we

176 identified the threshold of percentage cheetah prey to differentiate between low and high

177 probable levels of conflict. On the premise that strata with high probable levels of conflict will

178 have a low suitability for the long-term survival of cheetahs, we calculated for each stratum the 
179 percentage grid cells with $\leq 20 \%$ cheetah prey. We then used the Natural Breaks (Jenks) function

180 in ArcMap 9.3.1 to classify the strata into five classes of relative landscape suitability. The

181 Natural Breaks (Jenks) function grouped similar values and maximized the differences between 182 classes.

183 We used presence and absence data of cheetahs to test our landscape classification of strata as

184 suitable (very high to low suitability combined) or unsuitable. Game ranchers and commercial

185 livestock farmers in the game ranching regions of the Central, Ghanzi, Ngamiland and North

186 East regional districts (Boast, 2014) reported the status of cheetahs on their properties in

187 questionnaire surveys $(N=89)$, conducted during 2012 and 2013. Cheetahs were reported as

188 present (visual sightings or tracks seen at least quarterly), transient (visual sightings or tracks

189 seen less frequently than quarterly), or absent (never seen cheetahs or its tracks). We used a chi-

190 square test with Bonferroni simultaneous confidence intervals (Byers, Steinhorst \& Krausman,

191 1984) to test the hypothesis that farmers reported cheetahs as present or absent in similar

192 proportions to the number of grid cells per suitable and unsuitable landscape classes.

193

194 Results

195

196 Cheetah prey occurred widely across Botswana, with the highest biomass in the Okavango Delta 197 and Kwando/Linyanti/Chobe river system in the Northern Conservation Zone and in the Tuli

198 Conservation Zone in eastern Botswana (Figure 2). Cheetah prey biomass was low across most

199 part of the Ngamiland Agricultural Zone in the north-west. Small stock occurred widely across

200 the agricultural zones, but was unevenly distributed (Figure 3). The percentage cheetah prey

201 differed markedly between the strata identified in the agricultural zones (Figure 4). A list of 
202 strata names and identification numbers are supplied in Data S3. In the eastern parts of the

203 Central Agricultural Zone (stratum 5.3), and in the Kgalagadi Agricultural Zone 1 (stratum 8.3),

204 the Makgadikgadi Pans Community stratum (stratum 5.6), and the two strata surrounding the

205 Okavango Delta (strata 6.2 and 6.4), cheetah prey contributed only $0-5 \%$ of the total biomass

206 (cheetah prey plus small stock). This indicates very high probable levels of conflict in these 207 areas.

208 Livestock attacks recorded per grid cell for the percentage cheetah prey biomass intervals 209 ranged from 0.23 to 0.81 attacks per grid cell with a mean of 0.49 and standard error of $0.25(N=$

210 8) (Table 2). The number of attacks was consistently below the mean when the percentage

211 cheetah prey biomass exceeded $20 \%$. The observed frequency of attacks between the categories

212 of percentage cheetah prey differed significantly from the expected values $\left(\chi^{2}=52.42, \mathrm{df}=1, \mathrm{P}\right.$

$213<0.001)$ (Table 3). Livestock attacks were more than expected $(\mathrm{P}=0.05)$ in grids with $0 \%$

214 cheetah prey biomass, and significantly lower than expected in areas with $>20 \%(\alpha=0.05, \mathrm{Z}=$

215 2.4977). We therefore took grids with $\leq 20 \%$ cheetah prey biomass to represent areas with high

216 probable levels of conflict, and $>20 \%$ cheetah prey biomass to represent areas with low probable

217 levels of conflict.

218 Based on the percentage grid cells per stratum with $\leq 20 \%$ cheetah prey, we rated the five 219 classes of landscape suitability identified in ArcMap as very high ( $0-6.7 \%$ grids), high (6.8 $22025 \%$ grids $)$, medium ( $25.1-50 \%$ grids), low (50.1 - 75\% grids) or unsuitable $(75.1-100 \%$

221 grids) (Figure 5). Data S4 summarises the number of grid cells per stratum, the number and 222 percentage of grid cells with $\leq 20 \%$ cheetah prey, and the suitability class. The classification of 223 some strata as unsuitable for cheetahs was supported by the questionnaire data where the 224 proportion of farmers that reported cheetahs present or absent differed significantly between 
225 suitable and unsuitable areas $\left(\chi^{2}=129.11, \mathrm{df}=3, \mathrm{P}<0.001\right)$ (Table 4). Farmers reported

226 cheetahs absent in the unsuitable areas $(\mathrm{n}=10)$ significantly more than would be expected by

227 chance, and only $13.9 \%$ of farmers reported cheetahs absent within the suitable areas $(N=79)(\alpha$

$228=0.05, \mathrm{Z}=2.4977)$.

229

230 Discussion

231

232 Our analysis and the predictive suitability map presented provide a means for assessing the

233 landscape suitability within Botswana for cheetahs. We identified three important features of the

234 predictive map: land management in the agricultural areas to support a sufficient prey base for

235 cheetahs, maintaining connectivity between cheetah sub-populations within Botswana and across

236 its borders, and focal areas for the reduction of human-cheetah conflict.

237 The aerial survey data show that there is a good wild prey base for cheetahs across large parts

238 of the agricultural areas (Figure 2) despite the extensive distribution of small stock (Figure 3).

239 The high density of steenbok and duiker (range $0.261-4.319$ animals $/ 100 \mathrm{~km}^{2}$ ) in the tribal

240 grazing land of the Ghanzi Community Stratum (stratum 7.2) calculated from the six aerial

241 surveys, suggests that large and small livestock do not necessarily displace small ungulates to the

242 extent that large ungulates are displaced by cattle (Riginos et al., 2012). This greater resource

243 availability may be causal to the considerably higher density, smaller home range sizes, and

244 generally larger body size of cheetahs in Botswana compared to Namibia (Boast et al., 2013).

245 The significant reduction in livestock attacks in areas with $>20 \%$ cheetah prey biomass

246 showed that percentage cheetah prey biomass can be used to distinguish between high and low

247 levels of probable conflict on a landscape level. However, $20 \%$ cheetah prey as the likely critical 
248 point to distinguish between high and low probable levels of human-cheetah conflict is estimated

249 for Botswana and not necessarily valid for other landscapes. Furthermore, smaller-scale studies

250 using other methods to count wildlife (e.g. transect counts) should be conducted within

251 Botswana, to test whether the critical point we report here remains valid at finer scales of

252 investigation. The fact that livestock attacks by cheetahs decreased significantly with an increase

253 in percentage cheetah prey confirms the findings in Namibia and in Botswana that cheetahs

254 commonly prefer wild prey (Marker et al., 2003; Boast, 2014). A preference for wild prey has

255 also been shown for other large carnivores in areas where livestock is predominant (Hemson,

256 2003; Woodroffe et al., 2005a; Ogara et al., 2010). This trend would likely be supported by

257 efforts to maintain wild prey populations within livestock areas to decrease livestock depredation

258 (Mizutani, 1999; de Azevedo \& Murray, 2007). It is, however, important to note that the actual

259 occurrence of conflict is not uniformly spread across areas (Woodroffe, Thirgood \& Rabinowitz,

260 2005b; Holmern, Nyahongo \& Røskaft, 2007; Kushnir et al., 2010), and is determined by a more

261 complex array of factors than prey availability alone (Winterbach et al., 2013). Thus human-

262 wildlife conflict must also be assessed on a local level scale to guide mitigation strategies

263 (Muntefering et al., 2006).

264 The landscape suitability map (Figure 5) shows a number of important strata where the long-

265 term persistence of cheetahs is currently uncertain, and which may have a negative effect on

266 connectivity within the Botswana and for the regional southern African population. In the

267 Northern Conservation Zone, two strata surrounding the Okavango Delta (strata 6.2 and 6.4)

268 were ranked as unsuitable. This could hinder the free movement of cheetahs and thus reduce the

269 connectivity between Botswana's northern and southern sub-populations. In the south, a large

270 part of the Kgalagadi Agricultural Zone 2 was ranked as currently unsuitable or with a low 
271 suitability for cheetahs due to a low percentage prey. In addition, the increasing demand for

272 livestock grazing areas has led to a proposed change in land use from wildlife to cattle east of the

273 Ghanzi Community Stratum (stratum 7.2) (Botswana Ministry of Lands and Housing, 2008).

274 With extensive areas inside the Southern Conservation Zone already used for cattle production

275 (Conservation International Botswana, 2010), a barrier to large carnivore and wildlife movement

276 in general may well develop between Botswana's two largest protected areas: the Central

277 Kalahari Game Reserve and the Kgalagadi Transfrontier Park. Both these parks have a high

278 irreplaceability value in maintaining connectivity for large carnivores and ungulates in Africa

279 (Wegmann et al., 2014). Almost half of the country's cheetah population occurs in the Southern

280 Conservation Zone. To safeguard the large and yet contiguous cheetah population in Botswana,

281 where widespread natural movements still allow substantial gene flow (Dalton et al., 2013),

282 conservation planning will have to address ways to secure effective wildlife corridors.

283 Linkage of cheetah populations between Botswana and neighbouring countries, especially

284 Namibia, are also crucial to cheetah conservation. Namibia and Botswana protect approximately

$28577 \%$ of the southern African cheetah population (IUCN/SCC, 2007). According to the cheetah

286 range map provided by Marker et al. (2007) for Namibia, the most important population linkage

287 between the two countries lies in the Ghanzi Agricultural Zone. Our analysis gave the Ghanzi

288 Farms stratum (stratum 7.1), which consists of commercial game and livestock farms, a rank of

289 medium suitability for cheetahs (Figure 5). This is in concurrence with Kent (2010) who found a

290 reduced but healthy wild prey base, high human-cheetah conflict, and an estimated cheetah

291 density of 0.61 and 1.30 cheetahs $/ 100 \mathrm{~km}^{2}$. This is higher than the range of cheetah densities

292 (0.1 - 0.35 cheetahs $/ 100 \mathrm{~km}^{2}$ ) found on Namibian farmlands (Marker et al., 2007). In the

293 Ghanzi Community stratum (stratum 7.2) to the south, which consists of communal grazing land, 
294 cheetah prey biomass was high but the percentage cheetah prey was low; human-cheetah conflict 295 was thus predicted to be high. Its rank of low suitability is in concurrence with Muir (2009) who

296 found cheetahs were rarely reported by farmers or wildlife officers in the Hanahai Tribal Grazing

297 Area, which falls within this stratum. Conflict with humans, rather than prey availability thus

298 seems to be the major factor affecting the survival of cheetahs in the Ghanzi Conservation Zone.

300 Conclusions

301 Botswana's landscape provides large tracts of land that are suitable for the long-term-persistence

302 cheetahs. However, our predictive map highlights areas within Botswana that warrant more

303 investigation and intervention by conservationists. Those areas that we predict to be unsuitable

304 for cheetahs, but are nonetheless important potential corridors for the species, should receive 305 particular attention. In these areas, we recommend that wildlife corridors are maintained either

306 on agricultural land with consultation with local farmers, or areas are set aside where farming

307 activities are limited. Where farmers and cheetahs currently coexist in Botswana, we recommend 308 that wild prey species be maintained at a level of at least $20 \%$ of the overall prey biomass as part

309 of a comprehensive conflict mitigation strategy.

310

\section{Acknowledgements}

312

313 Thanks to Laurie Marker, J. W. McNutt, E. Fabiano, R. Kotze and G. Potgieter for valuable

314 comments on the manuscript. This manuscript was made possible by the Department of Wildlife

315 and National Parks, Ministry of Environment, Wildlife and Tourism, Gaborone, Botswana. 


\section{References}

318

319 Bartlam-Brooks HLA, Bonyongo MC, Harris S. 2011. Will reconnecting ecosystems allow

320 long-distance mammal migrations to resume? A case study of a zebra Equus burchelli migration

321 in Botswana. Oryx 45:210-216.

322 Belbachir F, Pettorelli N, Wacher T, Belbachir-Bazi A, Durant SM. 2015. Monitoring rarity:

323 the critically endangered Saharan cheetah as a flagship species for a threatened ecosystem. PLoS

324 ONE 10:e0115136. Available at http://www.plosone.org.

325 Bergström R, Skarpe C. 1999. The abundance of large wild herbivores in a semi-arid savanna

326 in relation to seasons, pans and livestock. African Journal of Ecology 37:12-26.

327 Boast L. 2014. Exploring the causes of and mitigation options for human-predator conflict on 328 game ranches in Botswana: How is coexistence possible? D. Phil. Thesis, University of Cape 329 Town.

330 Boast LK, Houser AM, Good K, Gusset M. 2013. Regional variation in body size of the

331 cheetah (Acinonyx jubatus). Journal of Mammalogy 94(6):1293-1297.

332 Botswana Government. 2000. Botswana Aerial Survey Information System. Version 1.0.

333 Gaborone: Department of Wildlife and National Parks.

334 Botswana Ministry of Agriculture. 2011. Livestock sector. Available at 335 http://www.moa.gov.bw./downloads_agricultural_marketing_strategy.pdf.

336 Botswana Ministry of Lands and Housing. 2008. Review of the national land use map. Final

337 Report. Government of Botswana, Gaborone.

338 Broekhuis F, Cozzi G, Valeix M, McNutt JW, Macdonald DW. 2013. Risk avoidance in

339 sympatric large carnivores: reactive or predictive? Journal of Animal Ecology 82:1098-1105. 
340 Brooks CJ. 2005. The foraging behaviour of Burchell's zebra (Equus burchelli antiquorum). D.

341 Phil. Thesis, University of Bristol.

342 Byers R, Steinhorst RK, Krausman PR. 1984. Clarification of a technique for analysis of

343 utilization-availability data. Journal of Wildlife Management 48:1050-1053.

344 Central Statistics Office. 2014. Population and housing census 2011 analytical report. Available

345 at http://www.cso.gov.bw/images/analytical_report.pdf.

346 Clements HS, Tambling CJ, Hayward MW, Kerley GIH. 2014. An objective approach to

347 determining the weight ranges of prey preferred by and accessible to the five large African

348 carnivores. PLoS ONE 9(7):e101054. Available at http://www.plosone.org.

349 Conservation International Botswana. 2010. Consultancy to identify important habitats for

350 key wildlife in the Western Kgalagadi Conservation Corridor (WKCC). Conservation

351 International Botswana, Gaborone.

352 Creel S, Spong G, Creel NM. 2001. Interspecific competition and the population biology of

353 extinction-prone carnivores. In: Gittleman JL, Funk SM, Macdonald DW, Wayne RK eds.

354 Carnivore Conservation. Cambridge University Press, 35-60.

355 Dalton DL, Charruau P, Boast L, Kotzé A. 2013. Social and genetic population structure of

356 free-ranging cheetah in Botswana: implications for conservation. European Journal of Wildlife

357 Research 59:281-285.

358 de Azevedo FCC, Murray DI. 2007. Evaluation of potential factors predisposing livestock to

359 predation by jaguars. Journal of Wildlife Management 71:2379-2386.

360 Department of Surveys and Mapping. 2001. Botswana National Atlas. Available at

361 http://www.atlas.gov.bw. 
362 Durant SM. 2000. Living with the enemy: avoidance of hyenas and lions by cheetahs in the

363 Serengeti. Behavioral Ecology 11:624-632.

364 Durant S, Marker L, Purchase N, Belbachir F, Hunter L, Packer C, Breitenmoser-Würsten

365 C, Sogbohossou E, Bauer H. 2008. Acinonyx jubatus. Available at http://www.iucnredlist.org.

366 Fuller TK, Sievert PR. 2001. Carnivore demography and the consequences of changes in prey

367 availability. In: Gittleman JL, Funk SM, Macdonald DW, Wayne RK eds. Carnivore

368 Conservation. Cambridge University Press, 163-178.

369 Gittleman JL, Harvey P H. 1982. Carnivore home range size, metabolic needs and ecology.

370 Behavioural Ecology and Sociobiology 10:57-63.

371 Gusset M, Swarner MJ, Mponwane L, Keletile K, McNutt JW. 2009. Human-wildlife

372 conflict in northern Botswana: livestock predation by endangered African wild dog Lycaon

373 pictus and other carnivores. Oryx 43:67-72.

374 Hachileka E. 2003. Sustainability of wildlife utilization in the Chobe District, Botswana. South

375 African Geographic Journal 85:50-57.

376 Hanssen L, Stander P. 2004. Namibia Large Carnivore Atlas. Available at

377 http://www.desertlion.info/reports/atlas_July2004.pdf.

378 Hayward MW, O'Brien J, Kerley GIH. 2007. Carrying capacity of large African predators:

379 predictions and tests. Biological Conservation 139:219-229.

380 Hemson G. 2003. The ecology and conservation of lions: human-wildlife conflict in semi-arid

381 Botswana. D. Phil. Thesis, University of Oxford.

382 Holmern T, Nyahongo J, Røskaft E. 2007. Livestock loss caused by predators outside the

383 Serengeti National Park, Tanzania. Biological Conservation 135:518-526. 
384 IUCN/SCC. 2007. Draft regional conservation strategy for the cheetah and African wild dog in

385 Southern Africa. IUCN, Gland.

386 Jachmann H. 2002. Comparison of aerial counts with ground counts for large African

387 herbivores. Journal of Applied Ecology 39:841-852.

388 Kent VT. 2010. The status and conservation potential of carnivores in semi-arid rangelands,

389 Botswana. D. Phil. Thesis, Durham University.

390 Klein R. 2007. Status report for the cheetah in Botswana. In: Breitenmoser C, Breitenmoser U,

391 Durant S eds. Status and conservation needs of cheetahs in southern Africa. IUCN/Cat Specialist

392 Group, 14-21. Available at http://www.catsg.org.

393 Kushnir HH, Leitner H, Ikanda H, Packer C. 2010. Human and ecological risk factors for

394 unprovoked lion attacks on humans in Southern Tanzania. Human Dimensions of Wildlife

$395 \quad 15: 315-331$.

396 Lindsey PA, Davies-Mostert HT. 2009. South African action plan for the conservation of

397 cheetahs and African wild dogs. Report from a national conservation action planning workshop.

398 IUCN Cat Specialist Group, 17-19. Avaiable at

399 http://www.catsg.org/cheetah/05_library/5_2_strategies-\&-action-plans/Lindsey_\&_Davies-

400 Mostert_2009_South_African_NAP_for_cheetahs_and_wild_dogs.pdf

401 Marker L, Dickman A. 2004. Human aspects of cheetah conservation: lessons learned from the

402 Namibian farmlands. Human Dimensions of Wildlife 9:297-305.

403 Marker L, Dickman A, Wilkinson C, Schumann B, Fabiano E. 2007. The Namibian cheetah:

404 status report. In: Breitenmoser C, Breitenmoser U, Durant S eds. Status and conservation needs

405 of cheetahs in southern Africa. IUCN Cat Specialist Group, 4-13. Marker LL, Muntifering JR, 
406

407

408

409

410

411

412

413

414

415

416

417

418

419

420

421

422

423

424

425

426

Dickman AJ, Mills MGL, Macdonald DW. 2003. Quantifying prey preferences of free-ranging Namibian cheetahs. South African Journal of Wildlife Research 33:43-53.

Meissner HH. 1982. Theory and application of a method to calculate forage of wild southern

African ungulates for purposes of estimating carrying capacity. South African Journal of Wildlife Research 12:41-47.

Mizutani F. 1999. Impact of leopards on a working ranch in Laikipia, Kenya. African Journal of Ecology 37:211-225.

Muir MJ. 2009. Predator conservation and conflict in the rangelands of Western Botswana:

evaluating the strategies and conditions that mitigate livestock loss. D. Phil. Thesis, University of California.

Muntifering JR, Dickman AJ, Perlow LM, Hruska T, Ryan PG, Marker LL, Jeo RM. 2006.

Managing the matrix for large carnivores: a novel approach and perspective from cheetah (Acinonyx jubatus) habitat suitability modelling. Animal Conservation 9:103-112.

Ogada MO, Woodroffe R, Oguge NO, Frank LG. 2003. Limiting depredation by African carnivores: the role of livestock husbandry. Conservation Biology 17:1521-1530.

Ogara WO, Gitahi NJ, Andanje SA, Oguge N, Nduati DW, Mainga AO. 2010.

Determination of carnivores prey base by scat analysis in Samburu community group ranches in Kenya. African Journal of Environmental Science and Technology 4:540-546.

\section{Riginos C, Porensky LM, Veblen KE, Odadi WO, Sensenig R, Kimuyu D, Keesing F,}

Wilkerson ML, Young TP. 2012. Lessons on the relationship between livestock husbandry and biodiversity from the Kenya Long-term Exclosure Experiment (KLEE). Pastoralism 22:1-22. 
427 Schuette P, Creel C, Christianson D. 2013. Coexistence of African lions, livestock, and people

428 in a landscape with variable human land use and seasonal movements. Biological Conservation $429 \quad 157: 148-154$.

430 Selebatso M, Moe SR, Swenson JE. 2008. Do farmers support cheetah Acinonyx jubatus 431 conservation in Botswana despite livestock depredation? Oryx 42:430-436.

432 Theobald DM, Hobbs NT, Bearly T, Zack JA, Shenk T, Riebsame WE. 2000. Incorporating

433 biological information in local land-use decision making: designing a system for conservation 434 planning. Landscape Ecology 15:35-45.

435 Verlinden A. 1998. Seasonal movement patterns of some ungulates in the Kalahari ecosystem of 436 Botswana between 1990 and 1995. African Journal of Ecology 36:117-128.

437 Wegmann M, Santini L, Leutner B, Safi K, Rocchini D, Bevanda M, Latifi H, Dech S, 438 Rondinini C. 2014. Role of African protected areas in maintaining connectivity for large 439 mammals. Philisophical Transactions of the Royal Society B 369:20130193. Available at 440 http://dx.doi.org/10.1098/rstb.2013.0193.

441 Wingqvist GÖ, Dahlberg E. 2008. Botswana Environmental and Climate Change Analysis.

442 University of Gothenburg, Stockholm.

443 Winterbach CW, Winterbach HEK. 2003. Draft predator management strategy. Department 444 of Wildlife and National Parks, Gaborone, Botswana.

445 Winterbach HEK, Winterbach CW, Somers MJ, Hayward MW. 2013. Key

446 factors and related principles in the conservation of large African carnivores.

447 Mammal Review 43: 89-110. 
448 Winterbach HEK, Winterbach CW, Somers MJ. 2014. Landscape suitability in Botswana for

449 the conservation of its six large African carnivores. PLoS ONE 9(6):e100202. Available at

450 http://www.plosone.org.

451 Woodroffe R, Frank LG, Lindsey PA, ole Ranah MK, Romañach S. 2007. Livestock

452 husbandry as a tool for carnivore conservation in Africa's community rangelands: a case-control 453 study. Biodiversity Conservation 16:1245-1260.

454 Woodroffe R, Ginsberg JR. 1998. Edge effects and the extinction of populations inside 455 protected areas. Science 280:2126-2128.

456 Woodroffe R, Lindsey P, Romañach S, Stein A, ole Ranah SMK. 2005a. Livestock predation 457 by endangered African wild dogs (Lycaon pictus) in northern Kenya. Biological Conservation $458 \quad$ 124:225-234.

459 Woodroffe R, Thirgood S, Rabinowitz A. 2005b. The future of coexistence: resolving human460 wildlife conflicts in a changing world. In: Woodroffe R, Thirgood S, Rabinowitz A eds. People 461 and wildlife. Conflict or coexistence? Cambridge University Press, 388-405. 
Figure $\mathbf{1}_{\text {(on next page) }}$

Land use categories and predator management zones in Botswana.

Land use categories and predator management zones in Botswana. The predator management zones were identified in Winterbach, Winterbach \& Somers (2014). The Conservation Zone (CZ) comprises protected areas (national parks, game and forest reserves, and sanctuaries) and Wildlife Management Areas. The Agricultural Zone (AZ) comprises rangeland, residential, and mining areas. 


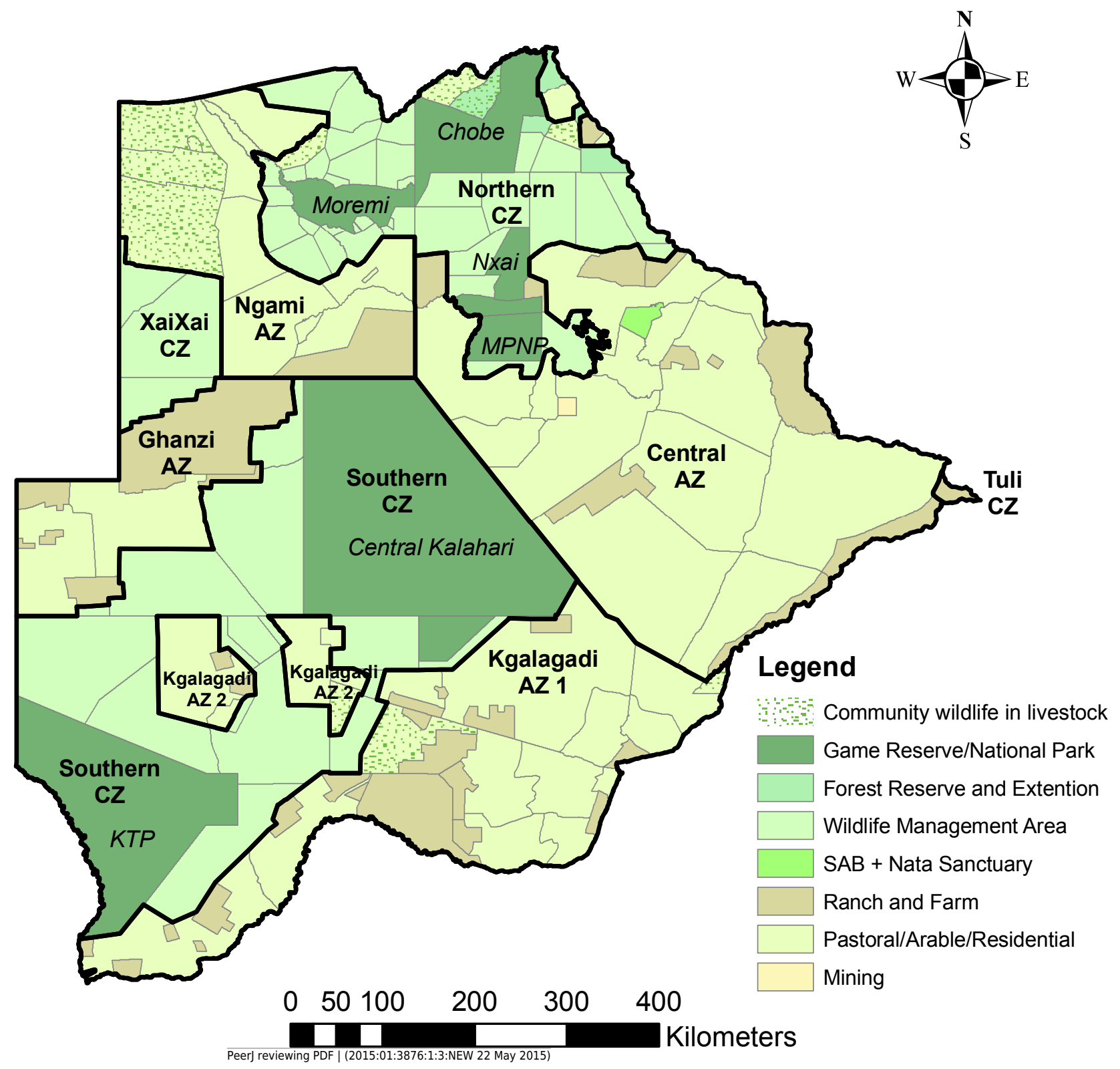


Figure 2 (on next page)

The distribution of cheetah prey biomass in Large Stock Units (LSU) across Botswana.

Cheetah prey are represented by those wild animal species counted in six aerial surveys across Botswana (2001 to 2005, and 2007) that are within the accessible prey weight range (body mass 14 - $135 \mathrm{~kg}$ ) for cheetahs, identified by Clements et al. (2014). The stratification of the Conservation and Agricultural Zones into strata is identified by number (Data S3). 


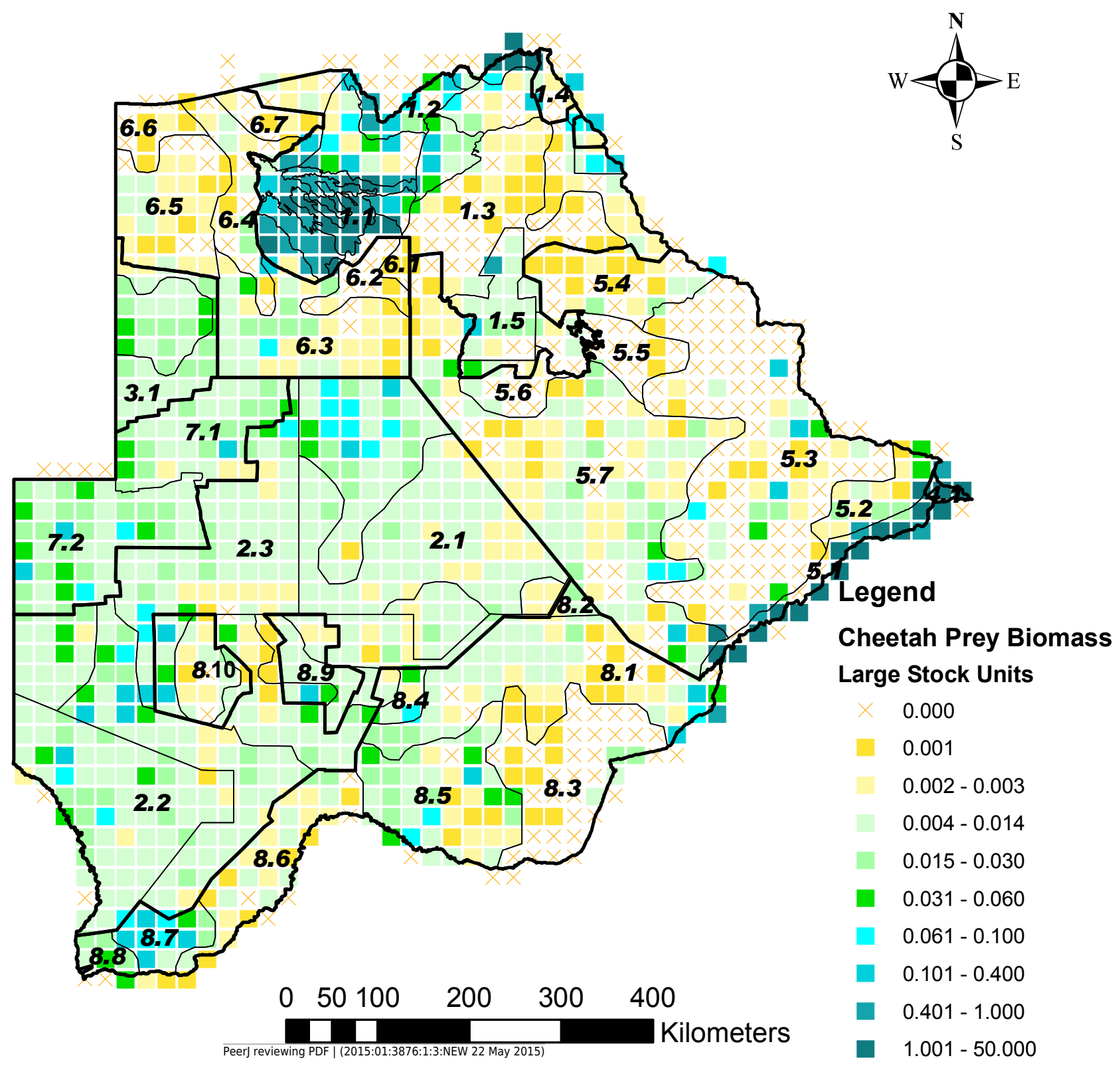


Figure 3 (on next page)

The distribution of small stock biomass in Large Stock Units (LSU) across Botswana.

Small stock is represented by goats and sheep as the main livestock whose depredation is a significant predictor of human-cheetah conflict levels in Botswana. This was illustrated by problem animal control (PAC) reports (Data S1). The stratification of the Conservation and Agricultural Zones into strata is identified by number (Data S3). 


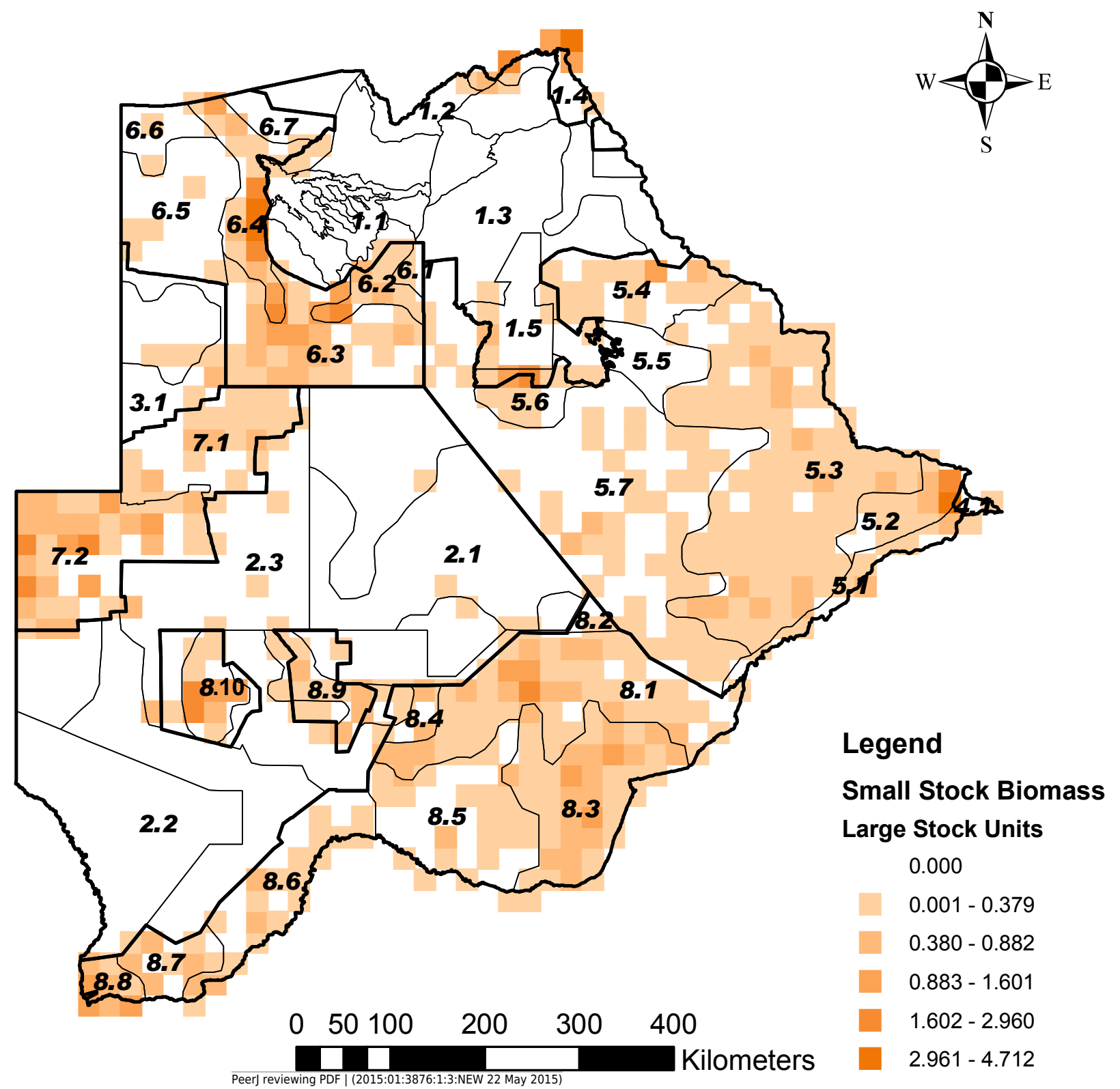


Figure 4 (on next page)

The distribution of the percentage cheetah prey biomass in Large Stock Units (LSU).

Percentage cheetah prey biomass is the proportion of cheetah prey biomass relative to the total biomass (cheetah prey and small stock biomass combined) and was used as a proxy for probable levels of human-cheetah conflict. A low percentage indicated high probable levels of conflict. The stratification of the Conservation and Agricultural Zones into strata is identified by number (Data S3). 


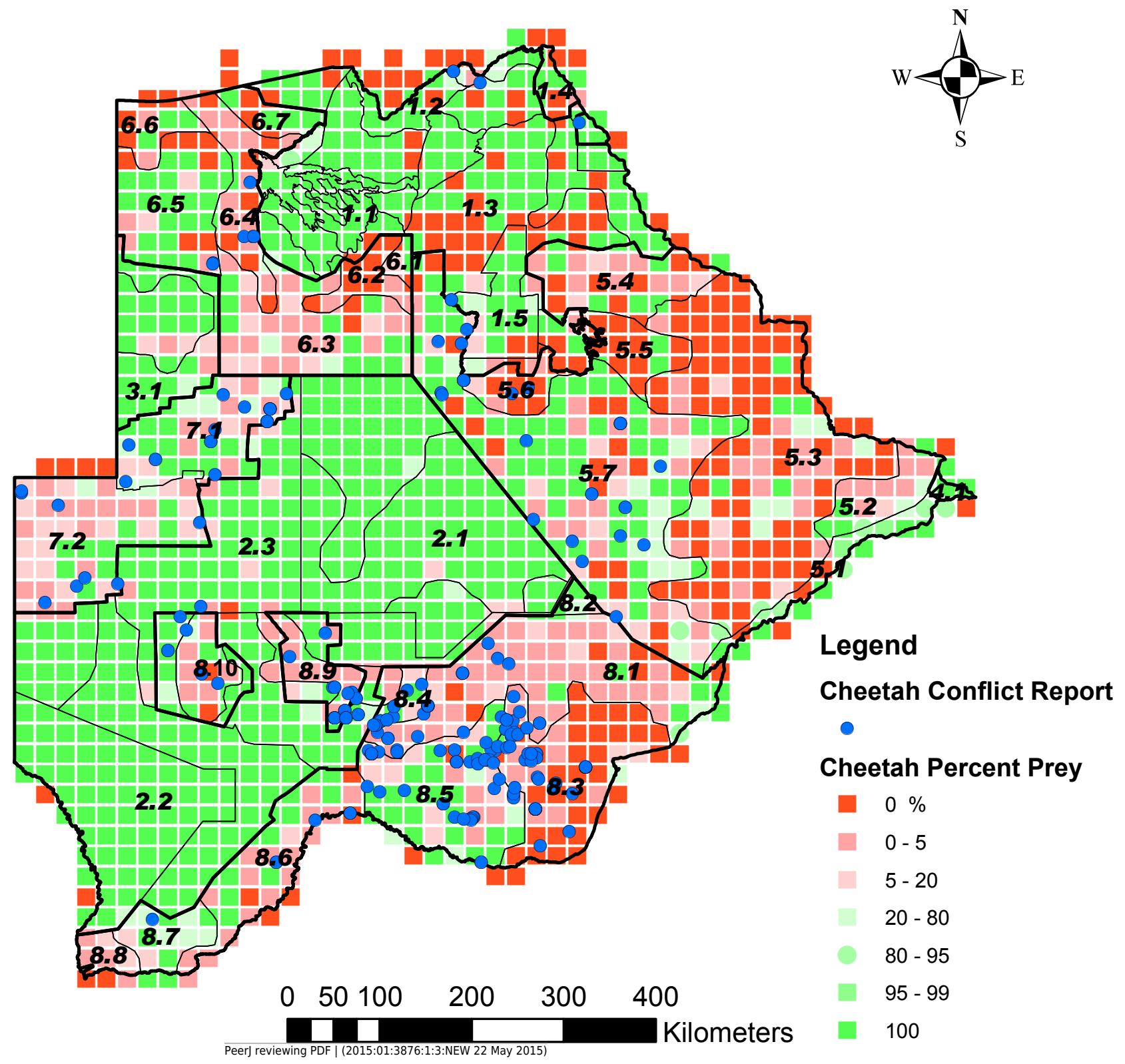


Figure 5 (on next page)

Predictive map showing the landscape suitability of the different strata in Botswana for the long-term persistence of cheetahs.

Suitability was assessed from the percentage grid cells per stratum with $\leq 20 \%$ cheetah prey biomass and the Natural Breaks (Jenks) function in ArcMap 9.3.1, to classify the strata into five classes of suitability. The stratification of the Conservation and Agricultural Zones into strata is identified by number (Data S3). 


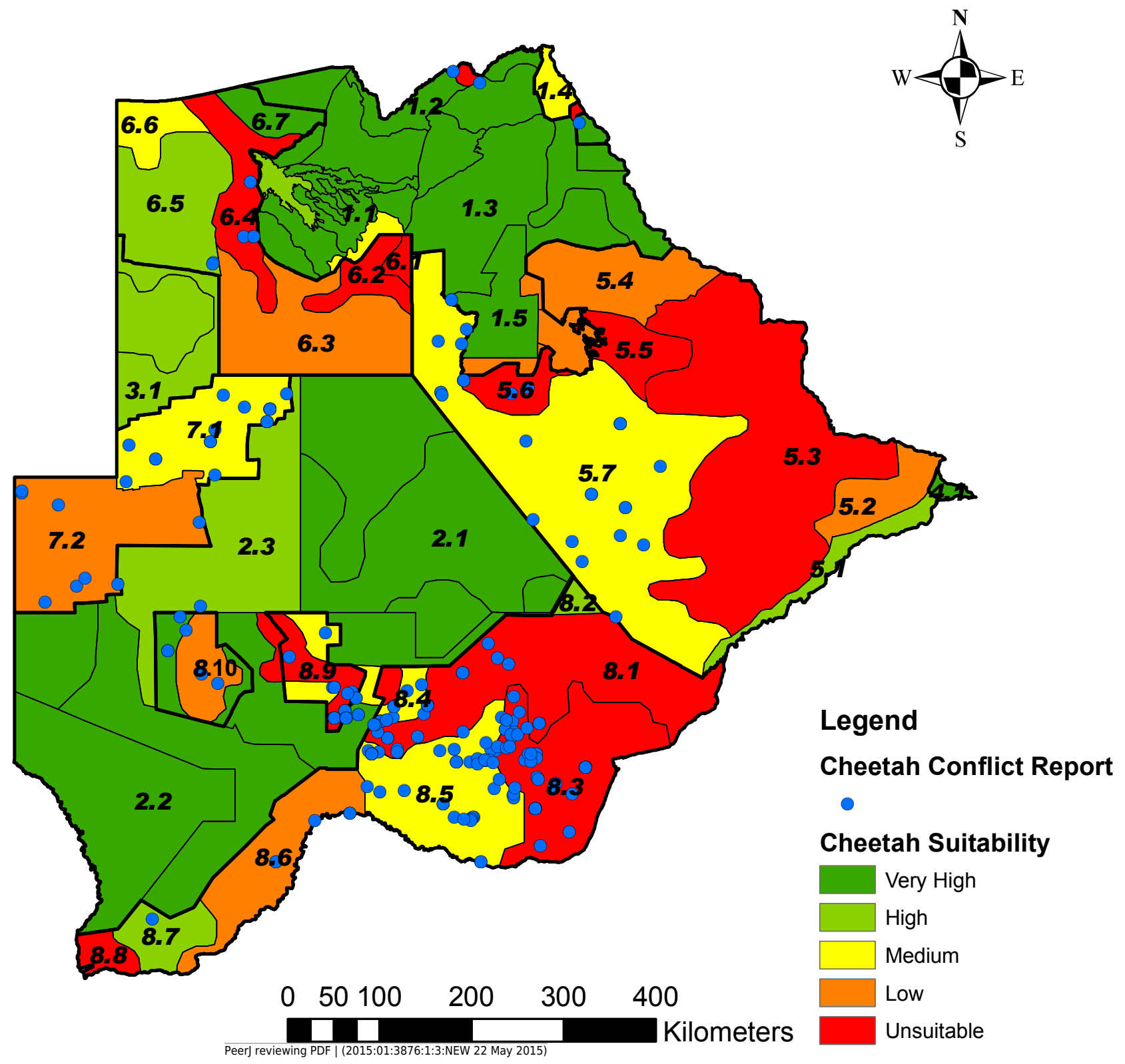


Table $\mathbf{1}$ (on next page)

Cheetah prey species masses $(\mathrm{kg})$ used in the conversion calculations from aerial survey counts to Large Stock Units (LSU) and the corresponding LSU values used to determine biomass.

${ }^{1}$ Source: Botswana Aerial Survey Information System database (Botswana Government, 2000). 


\begin{tabular}{l|lll}
\hline Species & Scientific name & ${\text { Weight }(\mathrm{kg})^{1}}$ & LSU conversion $^{l}$ \\
\hline Tsessebe & Damaliscus lunatus lunatus & 110 & 0.34764 \\
Red lechwe & Kobus leche & 72 & 0.25298 \\
Ostrich & Struthio camelus & 68 & 0.24237 \\
Warthog & Phacochoerus africanus & 45 & 0.17783 \\
Impala & Aepyceros melampus & 45 & 0.17783 \\
Reedbuck & Redunca arundinum & 40 & 0.16279 \\
Springbok & Antidorcas marsupialis & 26 & 0.11785 \\
Duiker & Sylvicapra grimmia & 15 & 0.07801 \\
Steenbok & Raphicerus campestris & 10 & 0.05756 \\
\hline
\end{tabular}


Table 2 (on next page)

The number of livestock attacks by cheetahs per 12' aerial survey grid in the different percentage cheetah prey intervals, and the overall mean number of attacks per grid.

The number of attacks was consistently below the mean when the percentage cheetah prey biomass exceeded $20 \%$. Livestock attacks occurred in the Kgalagadi and Ghanzi Agricultural Zones and the western strata of the Central Agricultural Zone between 1995 and 2005 (Klein, 2007). 


\begin{tabular}{l|lll}
\hline $\begin{array}{l}\text { Percentage cheetah } \\
\text { prey }\end{array}$ & Number of grids & $\begin{array}{l}\text { Number of livestock } \\
\text { attacks }\end{array}$ & Attacks per grid \\
\hline 0 & 43 & 34 & 0.79 \\
$>0$ to $\leq 1$ & 48 & 39 & 0.81 \\
$>1$ to $\leq 2$ & 33 & 9 & 0.27 \\
$>2$ to $\leq 5$ & 48 & 27 & 0.56 \\
$>5$ to $\leq 10$ & 40 & 9 & 0.23 \\
$>10$ to $\leq 20$ & 23 & 15 & 0.65 \\
$>20$ to $\leq 80$ & 32 & 8 & 0.25 \\
$>80$ to $\leq 100$ & 136 & 47 & 0.35 \\
TOTAL & 403 & 188 & $\mathbf{0 . 4 9}$ (mean) \\
\hline
\end{tabular}


Table 3 (on next page)

Bonferroni intervals to test for categories percentage cheetah prey with observed frequencies of livestock attacks by cheetahs that differed significantly from the expected $(k=4, \alpha=0.05, Z=2.4977)$.

A chi square test was used to determine if the number of grid cells $(N=403)$ (expected values) and the number of livestock attacks by cheetahs $(N=188)$ recorded (observed values) differed significantly for the four categories of percentage cheetah prey $\left(\chi^{2}=52.42\right.$, $\mathrm{df}=1, \mathrm{P}<0.001)$. From these results, $20 \%$ cheetah prey appears to be the critical point to differentiate between low and high probable levels of human-cheetah conflict. 


\begin{tabular}{l|lllll}
\hline Percentage & Expected & Observed & Bonferonni intervals & Use index & Significant \\
cheetah prey & Proportion & Proportion & for Pi & Pi/ Pio & \\
& Pio & $P i$ & & & \\
\hline 0 & 0.106700 & 0.180851 & $0.1107 \leq P i \leq 0.2510$ & 1.69 & + \\
$>0$ to $\leq 20$ & 0.476427 & 0.526596 & $0.4357 \leq P i \leq 0.6175$ & 1.11 & 0 \\
$>20$ to $\leq 80$ & 0.079404 & 0.042553 & $0.0058 \leq P i \leq 0.0793$ & 0.54 & - \\
$>80$ to $\leq 100$ & 0.337469 & 0.250000 & $0.1711 \leq P i \leq 0.3289$ & 0.74 & - \\
\hline
\end{tabular}




\section{Table 4(on next page)}

Bonferonni intervals for the presence, transience, and absence of cheetahs in areas deemed suitable and unsuitable for cheetahs in Botswana ( $k=4, \alpha=0.05, Z=2.4977$ ).

The proportion of farmers that reported cheetahs present or absent differed significantly between suitable and unsuitable areas $\left(\chi^{2}=129.11, \mathrm{df}=3, \mathrm{P}<0.001\right)$. Data were based on questionnaires completed by game ranchers and commercial livestock farmers $(N=89)$ during 2012 and 2013 in the game ranching regions of the Central, Ghanzi, Ngamiland and North East regional districts (Boast, 2014). 
2 Table 4. Simultaneous confidence intervals for the presence, transience, and absence of cheetahs based

3 on questionnaires completed by farmers $(N=89)$ in areas deemed suitable and unsuitable for cheetahs

4 in Botswana $(\mathrm{k}=4, \alpha=0.05, \mathrm{Z}=2.4977)$.

\begin{tabular}{l|lllll}
\hline & Expected & Observed & & \\
Observation & Proportion & Proportion & Bonferonni & Use index & \\
Type & Pio & $P i$ & intervals for Pi & Pi/Pio & Significant \\
\hline Absent in & & & & & \\
unsuitable & & & $0.0287 \leq \mathrm{Pi} \leq$ & & \\
area & 0.026462 & 0.112360 & 0.1960 & 4.25 & $*$ \\
Present in & & & & & \\
unsuitable & & & $0.0000 \leq \mathrm{Pi} \leq$ & & \\
area & 0.085687 & 0.000000 & 0.0000 & 0.00 & $*$ \\
Absent in & & & $0.0365 \leq \mathrm{Pi} \leq$ & & \\
suitable area & 0.209493 & 0.123596 & 0.2107 & 0.59 & 0 \\
Present in & & & $0.6516 \leq \mathrm{Pi} \leq$ & & \\
suitable area & 0.678358 & 0.764045 & 0.8765 & 1.13 & 0 \\
\hline
\end{tabular}

